NBER WORKING PAPER SERIES

\title{
21ST CENTURY MACRO
}

Narayana R. Kocherlakota

Working Paper 26791

http://www.nber.org/papers/w26791

\author{
NATIONAL BUREAU OF ECONOMIC RESEARCH \\ 1050 Massachusetts Avenue \\ Cambridge, MA 02138 \\ February 2020
}

I thank participants at a number of seminar presentations for their comments. The views expressed herein are those of the author and do not necessarily reflect the views of the National Bureau of Economic Research.

NBER working papers are circulated for discussion and comment purposes. They have not been peer-reviewed or been subject to the review by the NBER Board of Directors that accompanies official NBER publications.

(C) 2020 by Narayana R. Kocherlakota. All rights reserved. Short sections of text, not to exceed two paragraphs, may be quoted without explicit permission provided that full credit, including () notice, is given to the source. 
21st Century Macro

Narayana R. Kocherlakota

NBER Working Paper No. 26791

February 2020

JEL No. E12,E31,E52

\section{ABSTRACT}

In the 21st century, many key macroeconomic variables in the developed world have been persistently low, including inflation, output, growth, interest rates (both real and nominal), and labor share. I consider a class of standard representative agent rational expectations models in which fundamentals are deterministic and constant over time. I show that for any level of nominal frictions (no matter how small) and for any monetary policy rule (regardless of how active), there is a large set of stochastic equilibria that exhibit permanently low inflation, low output, low labor share, and low nominal interest rates. If the Phillips curve is sufficiently flat, then these equilibria also exhibit low growth and real interest rates.

Narayana R. Kocherlakota

Department of Economics

University of Rochester

202 Harkness Hall

P.O. Box 270156

Rochester, NY 14627

and NBER

nkocherl@ur.rochester.edu 


\title{
21st Century Macro
}

\author{
Narayana R. Kocherlakota*
}

February 2020

\begin{abstract}
In the 21st century, many key macroeconomic variables in the developed world have been persistently low, including inflation, output, growth, interest rates (both real and nominal), and labor share. I consider a class of standard representative agent rational expectations models in which fundamentals are deterministic and constant over time. I show that for any level of nominal frictions (no matter how small) and for any monetary policy rule (regardless of how active), there is a large set of stochastic equilibria that exhibit permanently low inflation, low output, low labor share, and low nominal interest rates. If the Phillips curve is sufficiently flat, then these equilibria also exhibit low growth and real interest rates.
\end{abstract}

\section{Introduction}

In the 21st century, many key macroeconomic variables in the developed world have been persistently low for a number of years, including:

- inflation (both expected and realized)

- output (both expected and realized)

${ }^{*}$ University of Rochester and NBER. I thank participants at a number of seminar presentations for their comments. 
- growth

- interest rates (both real and nominal)

In this paper, I consider a class of representative agent rational expectations models in which fundamentals are deterministic and constant over time. I show that, as long as there are any nominal frictions (no matter how small), then any monetary policy rule (regardless of how active) gives rise to a large set of stochastic equilibria that exhibit the above properties. Real determinacy of equilibrium (which is assumed in nearly all academic and policy macroeconomic analyses) is a property of a knife-edge set of models: those with zero pricing frictions.

The class of models that I study has two important features. First, I use a broader specification of nominal frictions than the standard one of costly price adjustment. The formulation of nominal frictions implies that, as long as they are non-zero, any level of real output is consistent with firm optimization. Second, I assume that firms can enter or exit by paying a finite cost. I show that the possibility of firm exit imposes an upper bound on output, but the possibility of firm entry fails to put a lower bound on (logged) aggregate output. Together, these two model elements give rise to my core result: it is impossible for central banks to eliminate the possibility of self-fulfilling stochastic equilibria with undesirably low levels of inflation and economic activity.

There is a large 20th century literature on sunspots and real indeterminacy in monetary economies that dates back at least to the classic work of Azariadis (1981) and Cass and Shell (1983). Benhabib and Farmer (1999)'s essay in volume 1 of the Handbook of Macroeconomics provides a thorough survey of the 20th century literature. In contrast, the thousands of pages of Volume 2 of the Handbook of Macroeconomics (Taylor and Uhlig, 2016) have only scattered and short references to equilibrium indeterminacy. The small number of references, as well as their substance, suggest that macroeconomists now view real indeterminacy as a problem that is being successfully avoided by wise governments through the use of appropriate policy 
rules. $^{1}$

This paper extends the 20th century indeterminacy research in an important way. That prior literature typically focused on showing that real indeterminacy is a property of a generic class of models. This paper goes further and demonstrates the converse: real determinacy is a property of a non-generic class of economic models - namely, those without nominal frictions. ${ }^{2}$ It follows that the conventional wisdom among 21st century macroeconomists - that real indeterminacy and sunspots can be (and has been) eliminated by sagacious government policy - is theoretically grounded in a knife-edge set of models.

Cochrane $(2011,2017)$ is also a skeptic of the 21st century consensus. He shows that in log-linearized Calvo models, as long as fiscal policy is passive (in the sense of Leeper (1991)), any monetary policy rule admits an enormous set of equilibria in which inflation and output may either grow or fall explosively. There are two key differences between my analysis and his. First, as is standard in Calvo models, he implicitly rules out the possibility of firm exit. I show that the possibility of (costly) firm exit allows the central bank to eliminate unduly high self-fulfilling inflation through active monetary policy rules. Second, I use a broader notion of nominal frictions which allows for the possibility that equilibrium inflation stays within a tight range, even though equilibrium output does not. ${ }^{3}$

The indeterminacy result in this paper can be seen as a generalization of Benhabib, Schmitt-Grohe, and Uribe (2001). They show that the existence of a lower bound on the nominal interest rate necessarily gives rise to an equilibrium in which inflation is constant at a negative rate and perpetually below the central bank's target level. Like them, I assume that there is a lower bound on the nominal interest rate. However, the formulation of nominal

\footnotetext{
${ }^{1}$ Farmer $(2019 a, 2019 b)$ is an important exception to this consensus view. He describes a research agenda ("Keynesian Search Theory") with indeterminate steady-states. Unlike this paper, he dismisses the role of nominal frictions and offers no explanation of the 21st century behavior of nominal variables like inflation.

${ }^{2}$ See Kocherlakota (2016) for a similar argument.

${ }^{3}$ More conjecturally, I suspect that Cochrane and I also differ in how we interpret our findings. I would say: almost all macro models imply that there is (downwardly biased) real indeterminacy, and so this is an important policy problem. I read Cochrane as instead saying: the New Keynesian models imply that there is equilibrium indeterminacy, and that means that they are deficient models which should not be used for policy purposes. But, as I say, this reading of Cochrane's work is more tentative.
} 
frictions in this paper implies that the low-inflation steady-state identified by Benhabib, et. al. may fail to exist. My main result shows that, even in these cases, there is a plethora of equilibria in which inflation and output are perpetually below target levels.

\section{Model Elements}

In this section, I describe the elements of the class of models that I use in the paper. The basic elements of the models (representative agent, Dixit-Stiglitz monopolistic competition, and monetary policy formulated in terms of an interest rate rule) are standard. However, I allow firms to enter or exit by paying a (large) finite cost. In the next section, I explain what I mean by "nominal frictions" and why entry/exit costs imply that logged output is bounded from above, but not from below.

\subsection{Households}

Consider an economy with a unit measure of households who live forever. Time is discrete and the households maximize the expected value of:

$$
\sum_{t=1}^{\infty} \beta^{t-1}\left(u\left(C_{t}\right)-v\left(N_{t}\right)\right), 0<\beta<1
$$

where $C_{t}$ is the consumption of a composite good in period $t$ and $N_{t}$ is labor in period $t$. Here, I assume that:

$$
\begin{aligned}
u^{\prime},-u^{\prime \prime}, v^{\prime}, v^{\prime \prime}>0 & \\
\lim _{c \rightarrow 0} u^{\prime}(c) & =\infty \\
\lim _{c \rightarrow \infty} u^{\prime}(c) & =0
\end{aligned}
$$

and that the functions $u, v$ are bounded from below by zero and from above by a finite number. 
The composite good consists of a measure $\nu$ of consumption goods, indexed by $j$, and is defined as:

$$
C_{t}=\left(\int_{0}^{\nu}\left(c(j)^{1-1 / \eta} d j\right)^{\frac{\eta}{\eta-1}}, \eta>1\right.
$$

Each household's consumption of each good $j$ is bounded from below by zero.

\section{$2.2 \quad$ Firms}

Each consumption good $j$ is produced in date $t$ by a monopolistically competitive firm that lasts for one period. (Their one-period nature means that entry/exit decisions are static.) A typical firm $j$ has a technology at each date $t$ that converts $x$ units of labor into $A x$ units

of consumption good $j$, for any $x \geq 0$, where $A$ is a positive constant. The households own equal shares of all firms.

Labor markets are competitive, and so, at each date, firms all hire workers at the same wage $W_{t}$ (denominated in terms of dollars). Given that wage, firms simultaneously set prices for their consumption goods in terms of dollars. The firms' problems are identical, and so they each choose the same price $P_{t}$ in equilibrium; that price is also the aggregate price level. I define the gross inflation rate $\pi_{t}$ as $P_{t} / P_{t-1}$.

Firms can exit (rather than producing) by paying a goods cost $k_{E X I T}>0$. A firm can enter (as a monopolist in a new good) by paying a goods cost $k_{E N T E R}>0$. In the New Keynesian literature, it is standard to set $k_{E X I T}$ and $k_{E N T E R}$ equal to infinity. I instead let $k_{E X I T}$ and $k_{E N T E R}$ be large but finite, and focus on equilibria in which existing firms find it optimal to not exit, and potential firms find it optimal to not enter.

\subsection{Policy}

Monetary policy works as follows. Each household is initially endowed with $\bar{M}_{0}$ dollars. Like reserves at many central banks, money is interest-bearing. Specifically, at the beginning of period $(t+1)$, a household that has $M_{t}$ dollars is paid $\left(R\left(\pi_{t}, Y_{t}\right)-1\right) M_{t}$ dollars. Here, the 
interest rate rule $R$ is an exogenous weakly increasing continuous function thats map period $t$ inflation and period $t$ output into a period $t$ gross nominal interest rate.

Finally, fiscal policy works as follows. The government's only liability is interest-bearing money. Let $\left[\bar{M}_{t}\right\}_{t=1}^{\infty}$ be an arbitrary (exogenous) sequence of positive real numbers. At each date $(t+1)$, the government levies a lump-sum tax, in dollars, equal to:

$$
\tau_{t}\left(\pi_{t}, Y_{t}\right)=\left(R\left(\pi_{t}, Y_{t}\right)-1\right) \bar{M}_{t}+\left(\bar{M}_{t}-\bar{M}_{t+1}\right)
$$

This (residually determined) tax ensures that the per-household level of nominal government liabilities at the end of period $(t+1)$ is equal to $\bar{M}_{t+1}$.

There is an additional linkage between monetary and fiscal policy. I assume that the (gross!) interest rate rule $R$ is bounded from below by $R_{\min }>0$, and that the time path of nominal government liabilities $\bar{M}$ satisfies:

$$
\lim _{T \rightarrow \infty} \bar{M}_{T+1} /\left(R_{m i n}\right)^{T}=0 .
$$

Note that, if the nominal interest rate lower bound $R_{\min }$ is below 1 , then this restriction requires the time path of nominal government liabilities to converge to zero exponentially. ${ }^{4}$

\section{Equilibrium Conditions}

In this economy, the exogenous monetary and fiscal policy are defined by $(R, \bar{M})$. Given this specification of policy, the endogenous equilibrium objects are (possibly stochastic) processes $(Y, W, P, \pi)$ that describe output, wages, prices, and inflation. In this section, I describe the relevant equilibrium conditions with and without nominal frictions.

\footnotetext{
${ }^{4}$ Throughout, I abstract from the existence of physical currency as a non-interest-bearing liability in positive supply that provides liquidity services. Adding currency would have two effects on the analysis. First, assuming that it is costless to store currency, its existence means that the nominal interest rate lower bound $R_{\min }$ cannot be lower than 1 . Second, the welfare costs associated with inefficient provision of liquidity would affect the choice of the government's desired output and inflation.
} 
The first three restrictions are independent of firm pricing. Inflation and prices are linked by the usual definitional relationship:

$$
\pi_{t+1}=P_{t+1} / P_{t}
$$

Households choose to supply labor at each date so as to satisfy the marginal condition:

$$
U^{\prime}\left(Y_{t}\right) W_{t}=V^{\prime}\left(Y_{t} / A\right) P_{t}
$$

Finally, their choices of consumptions at each date satisfy a sequence of Euler equations:

$$
U^{\prime}\left(Y_{t}\right)=\beta R\left(\pi_{t}, Y_{t}\right) E_{t}\left(U^{\prime}\left(Y_{t+1}\right) / \pi_{t+1}\right)
$$

Equilibrium processes must also satisfy a (necessary and sufficient) transversality condition, which restricts the long-run present value of the households' holdings of nominal government liabilities to be zero. But this condition is automatically satisfied in equilibrium through the joint restriction (1) on monetary and fiscal policy. In the language of Leeper (1991), (1) implies that fiscal policy is passive. In the language of Woodford (1995), it implies that fiscal policy is Ricardian.

\subsection{Pricing Restriction without Nominal Frictions}

At this point, we have three restrictions on four processes. To find the fourth restriction,

we need to turn to firm optimality (in terms of their pricing decisions). Suppose all firms simultaneously choose their prices from the positive reals. Then, in any period $t$, firm $j$ 's price choice must maximize:

$$
p_{j}\left(p_{j} / P_{t}\right)^{-\eta}-W_{t}\left(p_{j} / P_{t}\right)^{-\eta} / A
$$


where $P_{t}$ is the choice of all other firms and:

$$
W_{t}=\frac{v^{\prime}\left(Y_{t} / A\right)}{u^{\prime}\left(Y_{t}\right)} P_{t}
$$

Firm $j^{\prime} s$ optimal choice is:

$$
p_{j}=\frac{(1-1 / \eta)^{-1}}{A} P_{t} \frac{v^{\prime}\left(Y_{t} / A\right)}{u^{\prime}\left(Y_{t}\right)}
$$

Since all firms are solving the same problem, the fourth equilibrium restriction takes the form:

$$
Y_{t}=Y^{f l e x}
$$

where:

$$
v^{\prime}\left(Y^{f l e x} / A\right) / u^{\prime}\left(Y^{f l e x}\right)=A(\eta-1) / \eta
$$

\subsection{Nominal Frictions}

We have seen that, in the absence of nominal frictions, the level of output is pinned down by firm optimality. In the remainder of the paper, I instead consider the class of nominal frictions that give rise to an equilibrium condition of the form:

$$
\pi_{t}=\Pi^{P C}\left(Y_{t}\right)
$$

where $\Pi^{P C}$ is a weakly increasing and continuous function, with a domain equal to the positive reals. ${ }^{5}$ In the rest of this subsection, I describe two simple justifications for (4): money illusion and level-k firm thinking (Nagel (1995)). However, it is essential to keep in mind that these are only two of many possible rationalizations for (4), and that the results in the following section are valid for any of them. At the end of the subsection, I explain why Calvo and other forms of price adjustment frictions are not sufficient to deliver (4).

\footnotetext{
${ }^{5}$ In Section 5, I describe the impact of incorporating empirically relevant lags into (4)
} 


\subsubsection{Money Illusion}

In this subsection, I suppose that every firm $j$ behaves suboptimally by setting its price equal to a geometric weighted average of the best response to the prevailing nominal wage an indexed version of last period's price level:

$$
P_{j t}=\left((1-1 / \eta)^{-1} \frac{W_{t}}{A}\right)^{1-\theta}\left(\bar{\pi} P_{t-1}\right)^{\theta}
$$

Here, $\bar{\pi}$ is an exogenous indexation parameter. If all firms choose their prices in this way, then:

$$
\left.1=\left(A^{-1}(1-1 / \eta)^{-1} W_{t} / P_{t}\right)^{1-\theta}\left(\bar{\pi} P_{t-1} / P_{t}\right)\right)^{\theta}
$$

and so:

$$
\pi_{t}=\left(\frac{v^{\prime}\left(Y_{t} / A\right)}{A u^{\prime}\left(Y_{t}\right)}(1-1 / \eta)^{-1}\right)^{\frac{1-\theta}{\theta}} \bar{\pi}
$$

The firms' price-setting behavior implies that inflation is an increasing function of output $Y_{t}$. When $\theta$ is near zero, inflation is highly responsive to the current level of output. However, for any positive value of $\theta$, all positive values of $Y_{t}$ are consistent with this model of firm pricing. Hence, the slightest deviation from purely optimal firm behavior gives rise to a "Phillips curve" on inflation and output.

\subsubsection{Level k Firm Thinking}

In the previous subsection, all firms behave suboptimally. In this subsection, all firms behave optimally but believe that other firms are not behaving optimally.

Suppose firm $j$ assumes that all other firms set their period $t$ prices equal to $\bar{\pi} P_{t-1}$, where $\bar{\pi}$ is an exogenous parameter, and the level of output is $Y_{t}$. Then firm $j$ believes that the nominal wage depends on output as follows:

$$
\frac{v^{\prime}\left(Y_{t} / A\right)}{u^{\prime}\left(Y_{t}\right)} \bar{\pi} P_{t-1}
$$


and its optimal pricing response is to set $P_{j t}$ equal to:

$$
(1-1 / \eta)^{-1} \frac{v^{\prime}\left(Y_{t} / A\right)}{u^{\prime}\left(Y_{t}\right) A} \bar{\pi} P_{t-1} .
$$

If every firm have these same beliefs about other firms, then inflation is:

$$
\pi_{t}=\left((1-1 / \eta)^{-1} \frac{v^{\prime}\left(Y_{t} / A\right)}{u^{\prime}\left(Y_{t}\right) A}\right) \bar{\pi}
$$

The above is a description of level 1 thinking. Now suppose each firm believe that all other firms engage in level 1 thinking. Then each firm's optimal price is:

$$
\left((1-1 / \eta)^{-1} \frac{v^{\prime}\left(Y_{t} / A\right)}{u^{\prime}\left(Y_{t}\right) A}\right)^{2} \bar{\pi} P_{t-1}
$$

This is an example of level 2 thinking. We can keep iterating in this fashion, so that if firms engage in level $k$ thinking:

$$
\pi_{t}=\left((1-1 / \eta)^{-1} \frac{v^{\prime}\left(Y_{t} / A\right)}{u^{\prime}\left(Y_{t}\right) A}\right)^{k} \bar{\pi}
$$

As long as there is any deviation from common knowledge of rationality (so that $k$ is finite rather than infinite), there is a "Phillips curve" like relationship between inflation and output. For high values of $k$, inflation is highly sensitive to output (so that the slope of the Phillips curve is large in absolute value).

\subsubsection{Why Not Calvo?}

The restriction (4) is not consistent with the standard Calvo sticky price formulation. In the Calvo model, the degree of price flexibility affects the set of outputs that is consistent with firm optimality. In particular, if almost all firms can change their prices at each date, then 
they choose prices that give rise to aggregate demand that is $\operatorname{close}^{6}$ to $Y^{\text {flex. }}$. By way of contrast, in what follows, near-frictionless pricing only affects the responsiveness of inflation to output. It does not affect the set of outputs that are attainable in equilibrium.

What happens if we add Calvo elements (or other forms of price adjustment frictions) to the above models of firm behavior described in Sections 3.2.1 and 3.2.2? The distribution of lagged prices would affect current inflation. But it would still be true that firm pricing behavior would not restrict the set of possible aggregate outputs. It is in this sense that (4) represents a generalization of costly price adjustment frictions.

\subsection{Asymmetric Effects of Entry and Exit}

In this subsection, I describe the asymmetric effects of potential entry and exit on equilibrium output. This asymmetry plays a key role in the results in Section 4 .

The first observation is that potential exit generates a natural upper bound on output. A firm's equilibrium nominal profit, in any period $t$, is given by:

$$
\begin{array}{r}
P_{t} Y_{t}-W_{t} Y_{t} / A \\
=P_{t} Y_{t}\left(1-\frac{W_{t}}{A P_{t}}\right) \\
=P_{t} Y_{t}\left(1-\frac{v^{\prime}\left(Y_{t} / A\right)}{A u^{\prime}\left(Y_{t}\right)}\right)
\end{array}
$$

Note that:

$$
\lim _{Y \rightarrow \infty} Y\left(1-\frac{v^{\prime}(Y / A)}{A u^{\prime}(Y)}\right)=-\infty .
$$

The basic idea here is that, to generate high levels of output, firms must pay high real wages and so must earn highly negative profits.

Recall that firms can exit production in date $t$ by paying a cost $k_{E X I T}>0$ in terms of goods. Then, it is impossible for equilibrium output to exceed $Y^{U B}$, where $Y^{U B}$ is the largest

\footnotetext{
${ }^{6}$ I thank Ivan Werning for explaining this feature of the Calvo model to me. Note that this property is lost when the model is log-linearized.
} 
value of $Y$ that satisfies:

$$
\left(1-\frac{v^{\prime}(Y / A)}{A u^{\prime}(Y)}\right) Y \geq-k_{E X I T}
$$

For this reason, I focus on equilibria that are uniformly bounded from above by $Y^{U B}$. (As we shall see, we can choose $k_{E X I T}$ and $Y^{U B}$ to be arbitrarily large, without affecting the results.)

It may seem like a similar argument should imply that the entry cost would ensure that equilibrium output must be bounded away from zero. But that intuition turns out not to be correct. It is true that:

$$
\lim _{Y \rightarrow 0}\left(1-\frac{v^{\prime}(Y / A)}{u^{\prime}(Y) A}\right)=1
$$

so that firm profit share is close to one when aggregate output is near zero. But firm profits, when aggregate output is near zero, are given by:

$$
\lim _{Y \rightarrow 0} Y\left(1-\frac{v^{\prime}(Y / A)}{u^{\prime}(Y) A}\right)=0
$$

Firms are (naturally enough) making profits near zero when output is near zero. Throughout, I assume that:

$$
k_{E N T E R}>\max _{Y \geq 0} Y\left(1-\frac{v^{\prime}(Y / A)}{u^{\prime}(Y) A}\right)
$$

so that there is no entry in equilibrium. 


\subsection{Summary}

To sum up, an equilibrium is a stochastic process $(Y, \pi, W, P)$ that satisfies the following restrictions for $t=1,2,3, \ldots$ :

$$
\begin{aligned}
u^{\prime}\left(Y_{t}\right) W_{t} & =v^{\prime}\left(Y_{t} / A\right) P_{t}, \\
u^{\prime}\left(Y_{t}\right) & =\beta R\left(\pi_{t}, Y_{t}\right) E_{t} \frac{u^{\prime}\left(Y_{t+1}\right)}{\pi_{t+1}} \\
\pi_{t} & =\Pi^{P C}\left(Y_{t}\right) \\
\pi_{t} & =P_{t} / P_{t-1}, P_{0}=1 \\
Y_{t} & \leq Y^{U B}
\end{aligned}
$$

\section{Results}

In this section, I provide characterizations of equilibrium outcomes in the above class of models. The main point of the analysis is that there is an asymmetry associated with monetary policy. Active policy rules can eliminate above-target inflation equilibrium outcomes. However, no monetary policy rule, active or passive, can keep beliefs from giving rise to arbitrarily low equilibrium output.

Throughout the section, I consider a class of interest rate rules that satisfy the following restriction:

Restriction 1: There exists a target level of output $Y^{T A R}<Y^{U B}$ such that:

$$
\frac{\beta R\left(\Pi^{P C}\left(Y^{T A R}\right), Y^{T A R}\right)}{\Pi^{P C}\left(Y^{T A R}\right)}=1
$$

This restriction ensures that there is an equilibrium in which output is constant at the desired target level.

Proposition 1. Suppose that the interest rate rule $R$ satisfies Restriction 1. Then, there is 
an equilibrium in which:

$$
\begin{aligned}
Y_{t} & =Y^{T A R} \\
\pi_{t} & =\Pi^{P C}\left(Y^{T A R}\right) \\
\frac{W_{t}}{P_{t}} & =\frac{v^{\prime}\left(Y^{T A R} / A\right)}{u^{\prime}\left(Y^{T A R}\right)} \\
P_{t} & =\pi_{t} P_{t-1}, P_{0}=1
\end{aligned}
$$

with probability one for all $t \geq 1$.

Proof. It is readily verified that $(Y, \pi, P, W)$ satisfy the equilibrium conditions.

\subsection{The Lesson of the 1970s}

In the 1970s, inflation was high in much of the developed world. Clarida, Gali, Gertler (2000) present evidence that, in the United States, these outcomes were associated with the use of passive monetary policy rules (in which the nominal interest rate responds less than one-forone with inflation). They also present evidence that the adoption of active monetary policy rules was associated with the post-Volcker elimination of high-inflation outcomes. In this subsection, I show that these characterizations of US monetary policy and macroeconomic outcomes are consistent with this model.

\subsubsection{Above-Target Inflation}

I show first that interest rate rules that satisfy restriction 1 may admit many equilibria with above-target inflation if those rules are passive in a neighborhood of the target level of output.

Proposition 2. Consider any interest rate rule $R$ that satisfies restriction 1 such that:

$$
\frac{\beta R\left(\Pi^{P C}(Y), Y\right)}{\Pi^{P C}(Y)}
$$


is strictly decreasing as a function of $Y$ in a neighborhood of $Y^{T A R}$. Then, there exists a set of equilibria such that $\operatorname{Pr}\left(\pi_{t}>\pi^{T A R}\right)=1$ for all $t$.

Proof. In Appendix B.

\subsubsection{Getting Rid of High Inflation}

We can rule out equilibria with above-target inflation if the interest rate rule is active when output is above target.

Restriction 2: $\frac{\beta R\left(\Pi^{P C}(Y), Y\right)}{\Pi^{P C}(Y)}$ is strictly increasing for all $Y \geq Y^{T A R}$.

Restriction 2 says that the interest rate rule is active for output at or above $Y^{T A R}$. The following proposition shows that, because of the upper bound on output, the requirement of activeness implies that equilibrium output and inflation cannot exceed the target level.

Proposition 3. Suppose that the interest rate rule $R$ satisfies Restrictions 1 and 2. Then, in any equilibrium, $\operatorname{Pr}\left(Y_{t} \leq Y^{T A R}\right)=\operatorname{Pr}\left(\pi_{t} \leq \pi^{T A R}\right)=1$ for all $t \geq 1$. As well, in any equilibrium in which $\operatorname{Pr}\left(Y_{t}=Y^{T A R}\right)>0$ :

$$
\begin{aligned}
& \operatorname{Pr}\left(Y_{t+s}=Y^{T A R} \mid Y_{t}=Y^{T A R}\right)=1 \text { w.p. } 1 \text { for all } s \geq 1 \\
& \operatorname{Pr}\left(\pi_{t+s}=\pi^{T A R} \mid \pi_{t}=\pi^{T A R}\right)=1 \text { w.p. } 1 \text { for all } s \geq 1 .
\end{aligned}
$$

Proof. In Appendix B.

The key to the proof of this proposition is that, if $Y_{t}>Y^{T A R}$, the active interest rate rule implies that there is a positive probability path along which the marginal utility of consumption shrinks exponentially. But this implication violates the upper bound on output - that is, it would lead firms to exit production.

\subsection{Low Output Equilibria}

In this subsection, I prove the main result in the paper: any interest rate rule that satisfies Restriction 1 admits a large class of equilibria in which output is persistently below target. 
The next proposition establishes the existence of deterministic equilibria with this property. (Note that the proposition applies to all interest rate rules that satisfy Restriction 1, including those that do not satisfy Restriction 2.)

Proposition 4. Consider any interest rate rule $R$ that satisfies Restriction 1 and consider any $\bar{Y} \in\left(0, Y^{T A R}\right)$. Then, there is a deterministic equilibrium in which $Y_{1}=\bar{Y}$ and $Y_{t}<$ $Y^{T A R}$ for all $t \geq 2$.

Proof. The function:

$$
f(Y)=u^{\prime}(Y) / \Pi^{P C}(Y)
$$

is strictly decreasing in $Y$. Hence, $f$ is invertible; the domain of its inverse consists of the positive reals.

Now define:

$$
Y_{t+1}=f^{-1}\left(\frac{u^{\prime}\left(Y_{t}\right)}{\beta R\left(\Pi^{P C}\left(Y_{t}\right), Y_{t}\right)}\right)
$$

Suppose $Y_{t}<Y^{T A R}$. Then:

$$
\begin{aligned}
Y_{t+1} & =f^{-1}\left(\frac{u^{\prime}\left(Y_{t}\right)}{\beta R\left(\Pi^{P C}\left(Y_{t}\right), Y_{t}\right)}\right) \\
& <f^{-1}\left(\frac{u^{\prime}\left(Y^{T A R}\right)}{\beta R\left(\Pi^{P C}\left(Y_{t}\right), Y_{t}\right)}\right) \\
& \leq f^{-1}\left(\frac{u^{\prime}\left(Y^{T A R}\right)}{\beta R\left(\Pi^{P C}\left(Y^{T A R}\right), Y^{T A R}\right)}\right) \\
& =f^{-1}\left(\frac{u^{\prime}\left(Y^{T A R}\right)}{\Pi^{P C}\left(Y^{T A R}\right)}\right) \\
& =Y^{T A R} .
\end{aligned}
$$

The penultimate step relies on the assumption that $R$ and $\Pi^{P C}$ are both weakly increasing. Since $Y_{1}<Y^{T A R}$, by induction all elements of the sequence $\left(Y_{t}\right)_{t=1}^{\infty}$ are less than $Y^{T A R}$. 
The sequence $\left(Y_{t}\right)_{t=1}^{\infty}$ satisfies the Euler equation:

$$
\begin{aligned}
u^{\prime}\left(Y_{t}\right) & =f\left(Y_{t+1}\right) \beta R\left(\Pi^{P C}\left(Y_{t}\right), Y_{t}\right) \\
& =\frac{u^{\prime}\left(Y_{t+1}\right)}{\Pi^{P C}\left(Y_{t+1}\right)} \beta R\left(\Pi^{P C}\left(Y_{t}\right), Y_{t}\right)
\end{aligned}
$$

We can complete the definition of the equilibrium using:

$$
\begin{aligned}
\pi_{t} & =\Pi^{P C}\left(Y_{t}\right) \\
P_{t} & =P_{t-1} \pi_{t}, P_{0}=1 \\
W_{t} & =\frac{P_{t} v^{\prime}\left(Y_{t} / A\right)}{u^{\prime}\left(Y_{t}\right)} .
\end{aligned}
$$

The basic idea of Proposition 4 is that, given any period $t$ aggregate demand $Y_{t}<Y^{T A R}$, there is some belief about future $Y_{t+1}<Y^{T A R}$ that justifies that level of period $t$ demand.

The above proposition may remind some readers of the classic result of Benhabib, SchmittGrohe, and Uribe (2001). For a wide class of models, those authors show that if the nominal interest rate rule is bounded from below, then there are necessarily multiple steady-state inflation rates. However, the formulation of nominal frictions in this paper implies that their necessity result need not be valid. In particular, suppose the Phillips curve is sufficiently flat that:

$$
\frac{\beta R\left(\Pi^{P C}(Y), Y\right)}{\Pi^{P C}(Y)}<1
$$

for all $Y<Y^{T A R}$. (Note that this case, in which money pays a low real rate of return, is currently the empirically relevant one in much of the developed world.) Then, there is no steady-state in which inflation is constant and below target. Instead, the deterministic equilibrium in Proposition 4 is characterized by inflation that is declining to an asymptotic rate of $\lim _{Y \rightarrow 0} \Pi^{P C}(Y)$.

If the interest rate rule $R$ is active in a neighborhood of $Y^{T A R}$, then Proposition 4 can be 
strengthened to show that there is a continuum of low-output equilibria that are perpetually bounded away from $Y^{T A R}$.

Corollary 1. Let $R$ be any interest rate rule such that:

$$
\frac{\beta R\left(\Pi^{P C}(\hat{Y}), \hat{Y}\right)}{\Pi^{P C}(\hat{Y})} \leq 1
$$

for some $\hat{Y}<Y^{T A R}$. Consider any $\bar{Y} \in(0, \hat{Y})$. Then, there is a deterministic equilibrium in which $Y_{1}=\bar{Y}$ and $Y_{t}<\hat{Y}$ for all $t \geq 2$.

Proof. The proof is the same as the proof of Proposition 4, with $\hat{Y}$ substituted for $Y^{T A R}$.

We can generalize Proposition 4 to show that, given any interest rate rule that satisfies Restriction 1, there is a large class of stochastic equilibria in which output is always below target.

Proposition 5. Consider any interest rate rule $R$ that satisfies Restriction 1 and any $\bar{Y} \in$ $\left(0, Y^{T A R}\right)$. Let $\xi \equiv\left(\xi_{s}\right)_{s=2}^{\infty}$ be any stochastic process that satisfies the restrictions:

$$
\begin{aligned}
& E\left(\xi_{t+1} \mid \xi^{t}\right)=1 \text { for all } t \text { and almost all } \xi^{t} \\
& \operatorname{Pr}\left(\xi_{t+1}>\beta \frac{u^{\prime}\left(Y^{T A R}\right) \beta R\left(\Pi^{P C}\left(Y_{t}\right), Y_{t}\right)}{\Pi^{P C}\left(Y^{T A R}\right) u^{\prime}\left(Y_{t}\right)}\right)=1
\end{aligned}
$$

where $Y_{t}$ is defined recursively as a function of the history $\xi^{t}=\left(\xi_{2}, \ldots, \xi_{t}\right)$ :

$$
\begin{aligned}
\frac{u^{\prime}\left(Y_{t}\right)}{\Pi^{P C}\left(Y_{t}\right)} & =\frac{u^{\prime}\left(Y_{t-1}\right)}{\beta R\left(\Pi^{P C}\left(Y_{t-1}\right), Y_{t-1}\right)} \xi_{t} \\
Y_{1} & =\bar{Y}
\end{aligned}
$$

Then the output process $Y$ is part of an equilibrium and $\operatorname{Pr}\left(Y_{t}<Y^{T A R}\right)=1$ for all $t \geq 1$.

Proof. In Appendix B. 
It is straightforward to show that, under mild conditions on the interest rate rule and the Phillips curve, below target equilibrium output also implies that equilibrium inflation, nominal interest rates and labor share are below target.

Proposition 6. Suppose that the interest rate rule $R$ and the Phillips curve $\Pi^{P C}$ are both strictly increasing in a neighborhood of $Y^{T A R}$. In an equilibrium $(Y, \pi, P, W)$ such that $\operatorname{Pr}\left(Y_{t}<\right.$ $\left.Y^{T A R}\right)>0$, it is also true that:

$$
\begin{gathered}
\operatorname{Pr}\left(\pi_{t}<\pi^{T A R}\right)>0 \\
\operatorname{Pr}\left(\frac{W_{t}}{P_{t}}<\frac{A(\eta-1)}{\eta}\right)>0 \\
\operatorname{Pr}\left(R\left(\Pi^{P C}\left(Y_{t}\right), Y_{t}\right)<R\left(\Pi^{P C}\left(Y^{T A R}\right), Y^{T A R}\right)\right)>0
\end{gathered}
$$

Proof. The first two implications are immediate from the definition of equilibrium. The last implication follows from the supposition that $R\left(\Pi^{P C}(Y), Y\right)$ is strictly increasing as a function of $Y$ in a neighborhood of $Y^{T A R}$.

\subsection{Example Stochastic Equilibrium}

In this subsection, I describe an example of a stochastic equilibrium in which output is persistently below target. A key feature of the equilibrium is that the conditional downside risk to output is larger when output is further below target.

I define $\pi_{\min }=\lim _{Y \rightarrow 0} \Pi^{P C}(Y)$ and assume that $R_{\min }=\lim _{Y \rightarrow 0} R\left(\pi_{\min }, Y\right)$. Suppose that the interest rate rule $R$ satisfies:

$$
\frac{\left.\beta R\left(\Pi^{P C}(Y), Y\right)\right)}{\Pi^{P C}(Y)}=h\left(\frac{Y}{Y^{T A R}}\right)
$$

where $h$ is strictly increasing, $h(1)=1$, and $h(0)=\beta R_{\min } / \pi_{\min }<1$. Then, let $p$ be in $(0,1)$, 
and define the following Markov chain, assuming that $Y_{1}<Y^{T A R}$ :

$$
\begin{aligned}
& \operatorname{Pr}\left(Y_{t+1}=\bar{Y} \mid Y_{t}=\bar{Y}\right)=p \\
& \quad \operatorname{Pr}\left(Y_{t+1}=Y^{\prime}(\bar{Y}) \mid Y_{t}=\bar{Y}\right)=1-p
\end{aligned}
$$

Here, $Y^{\prime}(\bar{Y})$ is chosen so that:

$$
\frac{1}{h\left(\bar{Y} / Y^{T A R}\right)}=\left(p+(1-p) \frac{u^{\prime}\left(Y^{\prime}(\bar{Y})\right)}{u^{\prime}(\bar{Y})} \frac{\Pi^{P C}(\bar{Y})}{\Pi^{P C}\left(Y^{\prime}(\bar{Y})\right)}\right) .
$$

Since $h\left(\bar{Y} / Y^{T A R}\right)<1$ when $\bar{Y}<Y^{T A R}, Y^{\prime}(\bar{Y})<\bar{Y}$. In this Markov chain equilibrium, output either remains the same or transits to a new lower level. The size of the downward step in output depends on $Y_{t}$. If $Y_{t}$ is near $Y^{T A R}$, then the conditional variance of $Y_{t+1}$ is relatively small (because $h\left(Y_{t} / Y^{T A R}\right)$ is near 1$)$. In contrast, if $Y_{t}$ is near zero, then the conditional variance of $Y_{t+1}$ is shaped by $\frac{\beta R_{\min }}{\pi_{\min }}$.

\subsection{Low Growth and Low Real Interest Rates}

Propositions 4 and 5 show that there is a host of equilibria characterized by perpetually low output. In this subsection, I show how a sufficiently high lower bound on the Phillips curve implies that these results about levels translate into results about growth.

Proposition 7. Suppose that for all $Y>0, \Pi^{P C}(Y) \geq \pi_{\min }>\beta R_{\text {min }}$. Suppose too that there exists $Y^{*}<Y^{T A R}$ such that the interest rate rule $R$ satisfies

$$
\beta R\left(\Pi^{P C}\left(Y^{*}\right), Y^{*}\right) \leq \pi_{\min }
$$


Consider a deterministic equilibrium $(Y, \pi, P, W)$. If $Y_{t}<Y^{*}$ in period $t$,

$$
\begin{gathered}
Y_{t+1} / Y_{t}<1 \\
\frac{u^{\prime}\left(Y_{t}\right)}{\beta u^{\prime}\left(Y_{t+1}\right)}<\frac{1}{\beta} .
\end{gathered}
$$

Proof. The hypothesis is that, in period $t, \beta R\left(\Pi^{P C}\left(Y_{t}\right), Y_{t}\right)<\pi_{m i n}$. It follows that:

$$
\begin{aligned}
\frac{u^{\prime}\left(Y_{t}\right)}{\Pi^{P C}\left(Y_{t}\right)} & =\frac{\beta R\left(\Pi^{P C}\left(Y_{t}\right), Y_{t}\right)}{\Pi^{P C}\left(Y_{t}\right)} \frac{u^{\prime}\left(Y_{t+1}\right)}{\Pi^{P C}\left(Y_{t+1}\right)} . \\
& <\frac{u^{\prime}\left(Y_{t+1}\right)}{\Pi^{P C}\left(Y_{t+1}\right)} .
\end{aligned}
$$

and so $Y_{t}>Y_{t+1}$, which implies the proposition.

The key to this proposition is an assumption about the slope of the Phillips curve: as $Y$ falls to zero, the Phillips curve is sufficiently flat that that the minimal attainable inflation rate is higher than $\beta R_{\text {min }}$.

\subsection{Summary}

The propositions in this sections can be viewed as a sketch of the history of US monetary policy and macroeconomic outcomes over the past fifty years (since the end of the Bretton Woods monetary system). In the 1970s, US monetary policy was passive. The result was unduly high inflation (Proposition 2). By following active monetary policy, the US has eliminated high-inflation outcomes (Proposition 3).

However, there is no monetary policy rule that can eliminate the possibility of self-fulfilling equilibria in which output is persistently low (Propositions 4 and 5). In these equilibria, the nominal interest rate, inflation, and labor share are also persistently low (Proposition 6). If the slope of the Phillips curve is near zero (as appears to be true empirically), then the real interest rate and output growth are also low in these (deterministic) equilibria (Proposition 7). 
Section 4.3 provides an example of a stochastic low-output equilibrium in which the conditional variance of output is low when it is close to target, and high when it is well below target. We can use this example to interpret the Great Moderation (1985-2007) as a long period of time in which output was both close to target and displayed little volatility. ${ }^{7}$

\section{Comments}

In this section, I comment on five aspects of the above analysis: adding lags to the Phillips curve that links output and inflation, incorporating capital in the model, the exclusion of expectations from the monetary policy rules under consideration, the testability of macroeconomic models with multiple equilibria, and the passive nature of fiscal policy.

\subsection{Phillips Curve with Lags}

In the model considered in this paper, the Phillips curve relationship between inflation and output is static. Most estimated Phillips curves incorporate lagged inflation. This kind of relationship can be motivated using the reasoning in Section 3.2 by assuming that the benchmark inflation rate $(\bar{\pi})$ in Sections 3.2.1 and 3.2.2 depends on last period's inflation.

More formally, suppose that we replace the firm optimality restriction (4) with:

$$
\begin{aligned}
& \pi_{t}=\hat{\Pi}^{P C}\left(Y_{t}\right) \bar{\pi}\left(\pi_{t-1}\right), t>1 \\
& \pi_{1}=\hat{\Pi}^{P C}\left(Y_{1}\right) \bar{\pi}\left(\pi^{T A R}\right)
\end{aligned}
$$

where $\hat{\Pi}$ and $\bar{\pi}$ are both weakly increasing and continuous functions. Suppose too that the

\footnotetext{
${ }^{7}$ In the 1970s, much of the developed world experienced high unemployment in conjunction with high inflation. As is true of most models of that period, the framework in this paper can only account for these "stagflationary" episodes by adding shifters of some kind (such as mark-up shocks) to $\Pi^{P C}$. However, it is worth noting that the only restriction on $\Pi^{P C}$ is weak monotonicity. Hence, inflation can be highly sensitive to output when output is above $Y^{T A R}$ (as seemed to be true in the 1970s) while simultaneously being highly insensitive to output when $Y<Y^{T A R}$ (as seems to be true today).
} 
target inflation rate $\pi^{T A R}$ and target output satisfy the consistency condition:

$$
\frac{\pi^{T A R}}{\bar{\pi}\left(\pi^{T A R}\right)}=\hat{\Pi}^{P C}\left(Y^{T A R}\right)
$$

Then, we can prove the following version of Proposition 4.

Proposition 8. Suppose that the interest rate rule $R$ satisfies the restriction that:

$$
\beta \frac{R\left(\pi^{T A R}, Y^{T A R}\right)}{\pi^{T A R}}=1
$$

and suppose too that:

$$
\beta \frac{R(\pi, Y)}{\bar{\pi}(\pi)} \leq 1
$$

if $\pi \leq \pi^{T A R}$ and $Y \leq Y^{T A R}$. Then, in an economy with a lagged Phillips curve (11), and for any $\bar{Y} \in\left(0, Y^{T A R}\right)$, there is a deterministic equilibrium in which $Y_{1}=\bar{Y}$ and:

$$
\begin{aligned}
& Y_{t}<Y^{T A R} \\
& \pi_{t} \leq \pi^{T A R}
\end{aligned}
$$

for all $t=1,2, \ldots$

Proof. In Appendix B.

\subsection{Incorporating Capital}

In Appendix A, I extend the class of models to include capital. The extension is a standard one: I allow households to substitute consumption for capital on a one-to-one basis, and I assume the firms' production function is Cobb-Douglas in capital and labor. I treat the case in which the monetary policy rule specifies a constant and low real interest rate $r_{0} \leq 1 / \beta$ when output is low. Under this assumption, I show that if the initial level of capital is sufficiently low, there is a deterministic equilibrium in which output, capital, labor, and 
consumption all have the same constant non-positive growth rate.

The non-positivity of growth is a consequence of the assumption that there is no technological growth. With positive technological growth, we can re-state this result as saying that there is a continuum of balanced growth paths. Along any of these paths, all real aggregate variables (including labor input) have a constant growth rate that is no higher than the rate of growth of the technological frontier. ${ }^{8}$

\subsection{Rules with Expectations}

It is common in macroeconomics to assume that central banks follow forward-looking interest rate rules. For example, suppose that, at date $t$, the central bank knows that next period

output is governed by the random variable $\widetilde{Y}_{t+1}$. Suppose too that it sets the nominal interest rate according to the rule ${ }^{9}$

$$
R\left(Y_{t}, \widetilde{Y}_{t+1}\right)=u^{\prime}\left(Y^{T A R}\right) \beta^{-1}\left(E_{t} \frac{u^{\prime}\left(\widetilde{Y}_{t+1}\right)}{\Pi^{P C}\left(\widetilde{Y}_{t+1}\right)}\right)^{-1} .
$$

Then, the Euler equation implies that the households' period $t$ consumption must equal $Y^{T A R}$.

But the key presumption underlying these rules seems misplaced. How exactly is the central bank supposed to know the households' future choices (since they have not committed to those choices)? Presumably, the households could respond to a survey of some kind (which would be akin to allowing them to send messages to the central bank). However, the central bank faces the usual problem with surveys (or messages to social planners for that matter): there is nothing to ensure that the households' responses about the conditional distribution of future choices would align with their actual choices.

\footnotetext{
${ }^{8}$ It would be useful to also endogenize technological development, as in Benigno and Fornaro (2018).

${ }^{9}$ Adao, Correia, and Teles (2011) use these kinds of rules to ensure uniqueness.
} 


\subsection{Testability}

It is often argued that models that exhibit indeterminacy of equilibria lack empirical content. That claim is not true of the models in this paper. For example, in any equilibrium, the household labor supply condition:

$$
\frac{W_{t}}{P_{t}}=\frac{v^{\prime}\left(N_{t}\right)}{u^{\prime}\left(C_{t}\right)}
$$

is satisfied in every date and state. This (strong) restriction is falsifiable (with data on wages, prices, consumption, and labor), even without imposing the usual assumptions on $(u, v)$. Similarly, the model implies that:

$$
\pi_{t}=\Pi^{P C}\left(Y_{t}\right)
$$

so that there is a nonlinear monotonic deterministic relationship between output and inflation. The existence of such a relationship is again falsifiable using data on inflation and output.

This argument can be readily generalized. A model is a set of restrictions on observables. These restrictions may not jointly isolate a unique equilibrium for each specification of exogenous parameters. Nonetheless, as the above discussion illustrates, the restrictions typically still have (a great deal of) evaluable empirical content.

\subsection{Fiscal Theory of the Price Level?}

In the class of models in this paper, the limiting present value of government liabilities is assumed to be zero for any sequence of inflation rates. The intertemporal government budget constraint (or equivalently the household transversality condition) plays no role in the determination of equilibrium outcomes.

Can governments eliminate the low-inflation and low-output outcomes of the 21st century through an active fiscal regime? Cochrane (2019) would say yes. Buiter and Sibert (2018) would say no (because, in their view, active fiscal regimes are mis-specified). I remain firmly agnostic. However, it is worth noting that the relevant commitment about fiscal policy has to 
do with its limiting behavior (at the end of time itself). It is not clear to me how governments are supposed to make such long-term commitments credible.

\subsection{Highly Persistent Effects of Monetary Policy?}

In recent papers, Nakamura and Steinsson (2018) and Jorda, Singh, and Taylor (2020) find evidence that monetary policy has long-run effects on the economy. Proposition 5 in this paper suggests an explanation for their findings: agents could be using monetary policy shocks as a co-ordination device among sunspot equilibria. According to this view, if the central bank deviates in a surprising fashion from its rule, then the private sector could respond by co-ordinating on a different continuation equilibrium.

\section{Conclusions}

Since the collapse of the Bretton Woods monetary system in 1971, the monies of the developed world have been unbacked by any formal promise of convertibility. It might have been thought that this lack of backing would lead to overly high inflation and inflation expectations. Indeed, many countries experienced exactly this problem throughout the 1970s and 1980s. But governments and academic economists learned a key monetary policy lesson in the last part of the 20th century: even if currencies are unbacked, self-fulfilling bouts of unduly high inflation can be eliminated through the use of active monetary policy rules.

The main message of this paper is that this monetary policy lesson does not work in the opposite direction. I consider a large class of model economies that have a broader notion of nominal frictions than costly price adjustment. In these economies, there is an upper bound on logged output (imposed by the possibility of exit) but no lower bound. I show that, except in the knife-edge case of zero nominal frictions, any monetary policy rule admits a wide class of stochastic equilibria in which output and inflation are both perpetually below their desired levels. The result provides a robust explanation for why much of the developed world has 
been marked by persistently low output and low inflation in the 21st century.

As I discussed in the introduction, the current consensus among macroeconomists is that governments can (and do!) eliminate real indeterminacy through their choice of policy rules. That consensus means that, as Lucas (2003) argued, macroeconomic policy should focus mainly on the elimination of long-run supply-side distortions. The analysis in this paper calls that consensus into question. The robustness of downwardly biased real indeterminacy means that macroeconomic policymakers and macroeconomic researchers should be seeking answers to the following question: How can governments use communication and their other tools to ensure that economic actors co-ordinate beliefs and actions on desirable equilibria? Answering this question is essential to ensuring better macroeconomic outcomes than those experienced so far in the 21st century. 


\section{Appendix A}

In this appendix, I sketch what happens if we add capital to the models in Section 3. More specifically, I assume that there is an accumulation technology of the form:

$$
\begin{aligned}
C_{t}+K_{t+1} & =\left(\int y_{j t}^{1-1 / \eta} d j\right)^{\frac{\eta}{\eta-1}}+K_{t}(1-\delta) \\
K_{1} & =\bar{K}_{1}
\end{aligned}
$$

Firm j's production technology takes the Cobb-Douglas form:

$$
y_{j t}=A\left(k_{j t}\right)^{\alpha}\left(n_{j t}^{1-\alpha}\right)
$$

Here:

$$
\int k_{j t} d j=K_{t}
$$

It is no longer true that consumption and output are equal. Hence, the equilibrium restriction implied by the firms' pricing behavior takes the form:

$$
\pi_{t}=\Pi^{P C}\left(\psi_{t}\right)
$$

where $\psi_{t} \equiv(1-1 / \eta)^{-1} v^{\prime}\left(N_{t}\right) / u^{\prime}\left(C_{t}\right)$ is the correct measure of the output gap in this model with capital and $\Pi^{P C}$ is weakly increasing and continuous. Similarly, I define the interest rate rule $R$ as a weakly increasing and continuous function of $\left(\pi_{t}, \psi_{t}\right)$ rather than $\left(\pi_{t}, Y_{t}\right)$. The upper bound on output in the earlier model now becomes an upper bound on $\psi_{t}$. 
In this extended model, the deterministic equilibrium conditions are:

$$
\begin{aligned}
\psi_{t} & =v^{\prime}\left(N_{t}\right) / u^{\prime}\left(C_{t}\right) \\
u^{\prime}\left(C_{t}\right) & =\beta R\left(\pi_{t}, \psi_{t}\right) \frac{u^{\prime}\left(C_{t+1}\right)}{\pi_{t+1}} \\
u^{\prime}\left(C_{t}\right) & =\beta u^{\prime}\left(C_{t+1}\right)\left((1-\delta)+\alpha Y_{t} / K_{t}\right) \\
C_{t}+K_{t+1} & \left.=A K_{t}^{\alpha} N_{t}^{1-\alpha}+(1-\delta) K_{t}\right), K_{1}=\bar{K}_{1} \\
\pi_{t} & =\Pi^{P C}\left(\psi_{t}\right) \\
\pi_{t} P_{t-1} & =P_{t} \\
W_{t} & =P_{t} \psi_{t} \\
\psi_{t} & \leq \psi^{U B}
\end{aligned}
$$

We can use these equilibrium conditions to prove the following proposition for the case of logarithmic utility:

Proposition 9. Suppose $u(c)=\ln (c)$, and that there exists $\bar{\Psi}$ such that, for all $\psi \leq \bar{\Psi}$, $\Pi^{P C}(\psi)=\pi_{\min }$ and $R\left(\pi_{\min }, \psi\right)=R_{\text {min }}$. Suppose too that

$$
(1-\delta)<\frac{\beta R_{\min }}{\pi_{\min }} \leq 1
$$

Then, there exists $\bar{K}$ such that if initial capital $K_{1} \in[0, \bar{K}]$, then there is an equilibrium in which output, capital, labor, and consumption share a constant nonpositive growth rate.

Proof. Define:

$$
r_{0}=R_{\min } / \pi_{\min }
$$

and define $g=\beta r_{0}$. In a constant-growth equilibrium, the capital-output ratio and consumptionoutput ratio are constant at: 


$$
\begin{aligned}
& \hat{k}=\frac{\alpha}{r_{0}-1+\delta} \\
& \hat{c}=(1-\delta-g) \hat{k}+1
\end{aligned}
$$

respectively. (The former relationship is an implication of the capital Euler equation, and the second is an implication of the aggregate capital accumulation equation.) Pick the initial level of capital $\bar{K}_{1}$ so that:

$$
(\hat{c} / \hat{k}) \bar{K}_{1} v^{\prime}\left((\hat{k})^{\frac{1}{\alpha-1}} A^{\frac{1}{\alpha-1}} \bar{K}_{1}\right) \leq \bar{\Psi}
$$

and define $K_{t+1}=g K_{t}, K_{1}=\bar{K}_{1}$. Now, let:

$$
\begin{aligned}
C_{t} & =(\hat{c} / \hat{k}) K_{t} \\
Y_{t} & =K_{t} / \hat{k} \\
N_{t} & =(\hat{k})^{\frac{1}{\alpha-1}} A^{\frac{1}{\alpha-1}} K_{t}
\end{aligned}
$$

Then, it is readily verified that:

$$
\left(C_{t}, K_{t+1}, Y_{t}, N_{t}\right)_{t=1}^{\infty}
$$

satisfy the various equilibrium conditions with initial capital equal to $\bar{K}_{1}$, the nominal interest rate equal to $R_{m i n}$, and inflation equal to $\pi_{m i n}$.

\section{Appendix B}

In this appendix, I collect the remaining proofs (of Propositions 2, 3, 5, and 8). 


\section{Proof of Proposition 2}

There exists $\epsilon$ such that:

$$
\frac{\Pi^{P C}(Y)}{\beta R\left(\Pi^{P C}(Y), Y\right)}>1
$$

for all $Y$ in $\left(Y^{T A R}, Y^{T A R}+\epsilon\right)$. Pick any $Y_{1}$ in $\left(Y^{T A R}, Y^{T A R}+\epsilon\right)$ and, given that $Y_{1}$, recursively define a sequence $\left\{Y_{t+s}\right\}_{s=1}^{\infty}$ :

$$
\frac{u^{\prime}\left(Y_{t+1}\right)}{\Pi^{P C}\left(Y_{t+1}\right)}=\frac{\Pi^{P C}\left(Y_{t}\right)}{\beta R\left(\Pi^{P C}\left(Y_{t}\right), Y_{t}\right)} \frac{u^{\prime}\left(Y_{t}\right)}{\Pi^{P C}\left(Y_{t}\right)} .
$$

Suppose $Y_{t} \in\left(Y^{T A R}, Y^{T A R}+\epsilon\right)$. Since $\frac{\Pi^{P C}\left(Y_{t}\right)}{\beta R\left(\Pi^{P C}\left(Y_{t}\right), Y_{t}\right)}<1, Y_{t+1}<Y_{t}$. As well:

$$
\begin{aligned}
\frac{u^{\prime}\left(Y_{t+1}\right)}{\Pi^{P C}\left(Y_{t+1}\right)} & =\frac{u^{\prime}\left(Y_{t}\right)}{\beta R\left(\Pi^{P C}\left(Y_{t}\right), Y_{t}\right)} \\
& \leq \frac{u^{\prime}\left(Y_{t}\right)}{\beta R\left(\Pi^{P C}\left(Y^{T A R}\right), Y^{T A R}\right)} \\
& <\frac{u^{\prime}\left(Y^{T A R}\right)}{\Pi^{P C}\left(Y^{T A R}\right)}
\end{aligned}
$$

and so $Y_{t+1}>Y^{T A R}$. By induction, we can conclude that all elements of the sequence are in $\left(Y^{T A R}, Y^{T A R}+\epsilon\right)$.

For each sequence, we can construct an equilibrium:

$$
\begin{aligned}
\pi_{t} & =\Pi^{P C}\left(Y_{t}\right), t=1,2, \ldots \\
P_{t} & =\pi_{t} P_{t-1}, t=1,2, \ldots \\
W_{t} & =\frac{v^{\prime}\left(Y_{t} / A\right) P_{t}}{u^{\prime}\left(Y_{t}\right)} .
\end{aligned}
$$

In this equilibrium, $\pi_{t}>\Pi^{P C}\left(Y^{T A R}\right)$, because $Y_{t}>Y^{T A R}$. 


\section{Proof of Proposition 3}

Suppose $Y_{t}>Y^{T A R}$ with positive probability. Then, Restrictions 1 and 2 imply that:

$$
\frac{\beta R\left(\Pi^{P C}\left(Y_{t}\right), Y_{t}\right)}{\Pi^{P C}\left(Y_{t}\right)}>1
$$

in the event that $Y_{t}>Y^{T A R}$. It follows that there is a positive probability event in which:

$$
\frac{u^{\prime}\left(Y_{t+1}\right)}{\Pi^{P C}\left(Y_{t+1}\right)} \leq \frac{\Pi^{P C}\left(Y_{t}\right)}{\beta R\left(\Pi^{P C}\left(Y_{t}\right), Y_{t}\right)} \frac{u^{\prime}\left(Y_{t}\right)}{\Pi^{P C}\left(Y_{t}\right)} .
$$

This implies that $Y_{t+1}>Y_{t}$ in this event.

By induction, and using Restriction 2, we can show that for any $s>0$, there is a positive probability such that:

$$
\frac{u^{\prime}\left(Y_{t+s}\right)}{\Pi^{P C}\left(Y_{t+s}\right)} \leq\left(\frac{\Pi^{P C}\left(Y_{t}\right)}{\beta R\left(\Pi^{P C}\left(Y_{t}\right), Y_{t}\right)}\right)^{s} \frac{u^{\prime}\left(Y_{t}\right)}{\Pi^{P C}\left(Y_{t}\right)}
$$

But there exists some $s$ such that:

$$
\frac{u^{\prime}\left(Y^{U B}\right)}{\Pi^{P C}\left(Y^{U B}\right)}>\left(\frac{\Pi^{P C}\left(Y_{t}\right)}{\beta R\left(\Pi^{P C}\left(Y_{t}\right), Y_{t}\right)}\right)^{s} \frac{u^{\prime}\left(Y_{t}\right)}{\Pi^{P C}\left(Y_{t}\right)},
$$

which implies that there is a positive probability that $Y_{t+s}>Y^{U B}$. The first part of the proposition follows from this contradiction.

Now suppose that there is a positive probability event in which $Y_{t}=Y^{T A R}$. In that event:

$$
\frac{u^{\prime}\left(Y^{T A R}\right)}{\Pi^{P C}\left(Y^{T A R}\right)}=E_{t} \frac{u^{\prime}\left(Y_{t+1}\right)}{\Pi^{P C}\left(Y_{t+1}\right)} .
$$

and $Y_{t+1} \leq Y^{T A R}$. Together, these imply that $Y_{t+1}=Y^{T A R}$. The second part of the proposition then follows from induction. 


\section{Proof of Proposition 5}

We construct $(\xi, Y)$ inductively, starting with the assumption that $Y_{1}<Y^{T A R}$. Note that if $Y_{t}<Y^{T A R}$ with probability one, then:

$$
\begin{array}{r}
\left.\beta \frac{u^{\prime}\left(Y^{T A R}\right) \beta R\left(\Pi^{P C}\left(Y_{t}\right), Y_{t}\right)}{\Pi^{P C}\left(Y^{T A R}\right) u^{\prime}\left(Y_{t}\right)}\right) \\
\left.\leq \beta \frac{u^{\prime}\left(Y^{T A R}\right) \beta R\left(\Pi^{P C}\left(Y^{T A R}\right), Y^{T A R}\right)}{\Pi^{P C}\left(Y^{T A R}\right) u^{\prime}\left(Y_{t}\right)}\right) \\
\left.<\beta \frac{u^{\prime}\left(Y^{T A R}\right) \beta R\left(\Pi^{P C}\left(Y^{T A R}\right), Y^{T A R}\right)}{\Pi^{P C}\left(Y^{T A R}\right) u^{\prime}\left(Y^{T A R}\right)}\right) \\
=1
\end{array}
$$

with probability one. Hence, if $Y_{t}<Y^{T A R}$ with probability one, it is possible to find $\xi_{t+1}$ such that $E\left(\xi_{t+1} \mid \xi^{t}\right)=1$ and:

$$
\xi_{t+1}>\beta \frac{u^{\prime}\left(Y^{T A R}\right) \beta R\left(\Pi^{P C}\left(Y_{t}\right), Y_{t}\right)}{\Pi^{P C}\left(Y^{T A R}\right) u^{\prime}\left(Y_{t}\right)}
$$

with probability one. As well, the upper bound on $\xi_{t+1}$ implies

$$
\frac{u^{\prime}\left(Y_{t+1}\right)}{\Pi^{P C}\left(Y_{t+1}\right)}>\frac{u^{\prime}\left(Y^{T A R}\right)}{\Pi^{P C}\left(Y^{T A R}\right)}
$$

and $Y_{t+1}<Y^{T A R}$ with probability one.

Given the above process $Y$, we can define $(\pi, P, W)$ as:

$$
\begin{aligned}
\pi_{t} & =\Pi^{P C}\left(Y_{t}\right) \\
P_{t} & =\pi_{t} P_{t-1} \\
W_{t} & =\frac{P_{t} v^{\prime}\left(Y_{t} / A\right)}{u^{\prime}\left(Y_{t}\right)} .
\end{aligned}
$$


We can verify that $(Y, \pi, P, W)$ is an equilibrium by checking that the Euler equation holds:

$$
\begin{array}{r}
\beta R\left(\Pi^{P C}\left(Y_{t}\right), Y_{t}\right) E_{t}\left(\frac{u^{\prime}\left(Y_{t+1}\right)}{\prod^{P C}\left(Y_{t+1}\right)}\right) \\
=u^{\prime}\left(Y_{t}\right) E_{t} \xi_{t+1} \\
=u^{\prime}\left(Y_{t}\right) .
\end{array}
$$

and noting that, since $\operatorname{Pr}\left(Y_{t}<Y^{T A R}\right)$ with probability one, the upper bound on $Y$ is also satisfied.

\section{Proof of Proposition 8}

Since $Y_{1}<Y^{T A R}$, it follows that:

$$
\pi_{1}=\hat{\Pi}^{P C}\left(Y_{1}\right) \bar{\pi}\left(\pi^{T A R}\right) \leq \pi^{T A R}
$$

Consider any period $t$ in which $Y_{t}<Y^{T A R}$ and $\pi_{t} \leq \pi^{T A R}$. The Euler equation in period $t$ implies:

$$
\frac{u^{\prime}\left(Y_{t}\right) \bar{\pi}\left(\pi_{t}\right)}{\beta R\left(\pi_{t}, Y_{t}\right)}=\frac{u^{\prime}\left(Y_{t+1}\right)}{\hat{\Pi}^{P C}\left(Y_{t+1}\right)} .
$$

The left-hand side of (20) satisfies:

$$
\begin{aligned}
\frac{u^{\prime}\left(Y_{t}\right) \bar{\pi}\left(\pi_{t}\right)}{\beta R\left(\pi_{t}, Y_{t}\right)} & >\frac{u^{\prime}\left(Y^{T A R}\right) \bar{\pi}\left(\pi^{T A R}\right)}{\beta R\left(\pi^{T A R}, Y^{T A R}\right)} \\
& =\frac{u^{\prime}\left(Y^{T A R}\right)}{\hat{\Pi}^{P C}\left(Y^{T A R}\right)}
\end{aligned}
$$

The right-hand side of (20) is strictly increasing in $Y_{t+1}$. Hence, there is a unique $Y_{t+1}<Y^{T A R}$ that satisfies the period $t$ Euler equation. Because $\pi_{t} \leq \pi^{T A R}$, this level of output implies:

$$
\pi_{t+1}=\hat{\Pi}^{P C}\left(Y_{t+1}\right) \bar{\pi}\left(\pi_{t}\right) \leq \pi^{T A R}
$$


By induction, we can construct an equilibrium in which $Y_{t}<Y^{T A R}$ in all dates and inflation $\pi_{t} \leq \pi^{T A R}$ in all dates.

\section{References}

[1] Adao, B., Correia, I., and Teles, P., 2011, Unique monetary equilibria with interest rate rules, Review of Economic Dynamics 14, 432-442.

[2] Azariadis, C., 1981, Self-fulfilling prophecies, Journal of Economic Theory 25, 380-396.

[3] Benhabib, J., and Farmer, R., 1999, Indeterminacy and sunspots in macroeconomics, Handbook of Macroeconomics, Vol. 1, Part A, ed. Taylor, J., and Woodford, M., 387-448.

[4] Benhabib, J., Schmitt-Grohe, S., and Uribe, M., 2001, The perils of Taylor rules, Journal of Economic Theory 96, 40-69.

[5] Benigno, P. and Fornaro, L, 2018, Stagnation traps, Review of Economic Studies 85, $1425-1470$.

[6] Buiter, W., and Sibert, A., 2018, The fallacy of the fiscal theory of the price level one last time, Economics: The Open-Access, Open-Assessment E-Journal, 12 (2018-48), $1-56$.

[7] Cass, D., and Shell, K., 1983, Do sunspots matter?, Journal of Political Economy 91, $193-227$.

[8] Clarida, R., Gali, J., and Gertler, M., 2000, Monetary policy rules and macroeconomic stability: Evidence and some theory, Quarterly Journal of Economics 115, 147-180.

[9] Cochrane, J., 2011, Determinacy and identification with Taylor Rules, Journal of Political Economy 119, 565-615. 
[10] Cochrane, J., 2017, Michelson, Morley, Fisher, and Occam: The radical implications of stable quiet inflation at the zero bound, NBER Macroeconomics Annual 2017, ed. Eichenbaum, M. E., and Parker, J. A., 113-226.

[11] Cochrane, J. 2019, The Fiscal Theory of the Price Level, draft book.

[12] Farmer, R., 2019a, The indeterminacy agenda in macroeconomics, NBER working paper 25879.

[13] Farmer, R., 2019b, The importance of beliefs in shaping macroeconomic outcomes, NBER working paper 26557.

[14] Jorda, O., Singh, S., and Taylor, A., 2020, The long-run effects of monetary policy, NBER working paper 26666.

[15] Kocherlakota, N. 2016, Fragility of purely real macroeconomic models, NBER working paper 21866 .

[16] Leeper, E., Equilibria under "active" and "passive" monetary policies, Journal of Monetary Economics 27, 129-147.

[17] Lucas, R. E., Jr., 2003, Macroeconomic priorities, American Economic Review 93, 1-14.

[18] Nagel, R., 1995, Unraveling in guessing games: An experimental study, American Economic Review 85, 1313-1323.

[19] Nakamura, E., and Steinsson, J., 2018, High-frequency identification of monetary nonneutrality: The information effect, Quarterly Journal of Economics 133, 1283-1330.

[20] Taylor, J., and Uhlig, H., ed., 2016, Handbook of Macroeconomics, Vol. 2.

[21] Woodford, M., Price level determinacy without control of a monetary aggregate, Carnegie-Rochester Conference Series on Public Policy 43, 1-46. 